\title{
MILITARY JET PILOTS HAVE HIGHER P-WAVE DISPERSIONS COMPARED TO THE TRANSPORT AIRCRAFT AIRCREW
}

\author{
MUSTAFA ÇAKAR ${ }^{1}$, SÜLEYMAN METIN² ${ }^{2}$ ŞEVKET BALTA ${ }^{3}$, CENGIZ ÖZTÜRK ${ }^{4}$, SAIT DEMİRKOL ${ }^{4}$, \\ TOLGA ÇAKMAK ${ }^{2}$, SATILMIŞ INAL ${ }^{1}$, TURGAY ÇELIKK ${ }^{4}$, ATILLA IYISOY ${ }^{4}$, MURAT ÜNLÜ ${ }^{4}$, and AHMET ŞEN ${ }^{2}$
}

${ }^{1}$ Eskisehir Military Hospital, Eskisehir, Turkey

Department of Internal Medicine

${ }^{2}$ Gulhane Medical Academy, Eskisehir, Turkey

Department of Aerospace Medicine

${ }^{3}$ Eskisehir Military Hospital, Eskisehir, Turkey

Department of Cardiology

${ }^{4}$ Gulhane Medical Academy, Ankara, Turkey

Department of Cardiology

\begin{abstract}
Objectives: For the purpose of flight safety military aircrew must be healthy. P-wave dispersion (PWD) is the p-wave length difference in an electrocardiographic (ECG) examination and represents the risk of developing atrial fibrillation. In the study we aimed at investigating PWD in healthy military aircrew who reported for periodical examinations. Material and Methods: Seventy-five asymptomatic military aircrew were enrolled in the study. All the subjects underwent physical, radiologic and biochemical examinations, and a 12-lead electrocardiography. P-wave dispersions were calculated. Results: The mean age of the study participants was $36.15 \pm 8.97$ years and the mean p-wave duration was $100.8 \pm 12 \mathrm{~ms}$ in the whole group. Forty-seven subjects were non-pilot aircrew, and 28 were pilots. Thirteen study subjects were serving in jets, 49 in helicopters, and 13 were transport aircraft pilots. Thirty-six of the helicopter and 11 of the transport aircraft aircrew were non-pilot aircrew. P-wave dispersion was the lowest in the transport aircraft aircrew, and the highest in jet pilots. P-wave dispersions were similar in the pilots and non-pilot aircrew. Twenty-three study subjects were overweight, 19 had thyroiditis, 26 had hepatosteatosis, 4 had hyperbilirubinemia, 2 had hypertension, and 5 had hyperlipidemia. The PWD was significantly associated with thyroid-stimulating hormone (TSH) levels. Serum uric acid levels were associated with p-wave durations. Serum TSH levels were the most important predictor of PWD. Conclusions: When TSH levels were associated with PWD, uric acid levels were associated with p-wave duration in the military aircrew. The jet pilots had higher PWDs. These findings reveal that military jet pilots may have a higher risk of developing atrial fibrillation, and PWD should be recorded during periodical examinations.
\end{abstract}

Key words:

Atrial fibrillation, P-wave dispersion, Military aircrew, TSH, Jet pilots, Arrythmia

Received: December 30, 2014. Accepted: August 3, 2015.

Corresponding author: M. Çakar, Eskisehir Military Hospital, Department of Internal Medicine, 59 Atatürk Street, 26010, Eskisehir, Turkey (e-mail: drmustafacakar@gmail.com). 


\section{INTRODUCTION}

Apart from having to meet several professional qualifications, military aircrew should also meet physical and mental requirements mentioned in the relevant instructions and regulations. To make sure that the requirements are fulfilled, periodical examinations of the aircrew and an early diagnosis of medical diseases are necessary.

P-wave dispersion (PWD) has been defined as a difference between the shortest and longest p-wave duration recorded from multiple different surface electrocardiographic (ECG) leads, and has recently been introduced to the field of noninvasive electrocardiology [1]. Improvement in the methodology of recording and analyzing p-wave documentations leads to the widespread use of this ECG marker in various clinical conditions and, particularly, in the assessment of risk of arrhythmias, mainly atrial fibrillation (AF) [2]. Hypo-hyperthyroidism can pose a risk in terms of such cardiac rhythm disorders [3-5]. Atrial fibrillation is one of the most common encountered arrhythmias having catastrophic future risks, such as stroke. Additionally, it is encountered frequently in the current practice. It has been concluded that PWD may have a role in the diagnostics and therapeutic management of this arrhythmia [6]. It is not exactly known whether the factors, such as: flight stress, high altitude, hypobaric conditions or sudden movements, in time lead to the development of arrhythmias such as AF in pilots. Nevertheless, it is true that serious supraventricular arrhythmias, especially AF, may result in stroke or temporary loss of consciousness, and potentially lead to a disqualification from flying tasks. As far as we could reach in the literature, PWD and associated factors as a surrogate for potential arrhythmias in military aircrew have not been investigated before. In this study, we aimed at investigating factors associated with PWD that may pose risks in terms of the development of AF. Additionally, we aimed at defining the rationale and the fields for its clinical use in in the case of periodical examinations of healthy military aircrew.

\section{MATERIAL AND METHODS}

\section{Subjects}

The study was conducted in a secondary military referral health center. Our hospital is also a center for the yearly and 5-year periodical examinations of military aircrew. A total of 75 military aircrew, all of whom were male, reporting for 5-year periodical examinations were enrolled in the study. Military non-pilot aircrew are people helping with search-rescue jobs, transporting objects, carrying goods needed for the flight, etc., who fly with pilots together in helicopters and in transport aircrafts. Physical examination, blood pressure (BP) and anthropometric measurements were performed as part of the 5-year periodical examinations. The examinations also included obtaining information on the type of the aircraft they serve in, their tasks, drug history, smoking, alcohol usage and past medical history. Complete blood count, renal and hepatic function tests, electrolytes, serum lipid levels, thyroid hormones, serum thyroid antibodies, electrocardiographic and echocardiographic examinations were also performed within the examinations.

Exclusion criteria for the study participants were: refusal to participate in the study, smoking, uncontrolled hypertension, anemia, uncontrolled diabetes mellitus, left ventricular dysfunction (left ventricular ejection fraction $<50 \%$ ) or hypertrophy, acute coronary syndromes, valvular heart disease, congenital heart disease, renal or hepatic dysfunction (creatinine $>1.5 \mathrm{mg} / \mathrm{dl}$, aspartate aminotransferase and alanine transaminase $>2 x$ the upper limit of normal, respectively), known malignancy, local or systemic infection, previous history of infection ( $<3$ months), inflammatory diseases, and any medication that could potentially interfere with measurement of PWD. The subjects were divided into 3 groups according to the type of the aircraft they serve in: jet, helicopter and transport aircraft. The subjects were asked to rest for 10 min before BP was recorded, using a manual mercury sphygmomanometer. The mean 
of 2 BP measurements was considered. The mean arterial blood pressure was calculated according to the following formula:

$$
\mathrm{MAP}=\mathrm{DBP}+\frac{\mathrm{SBP}-\mathrm{DBP}}{3}
$$

where:

MAP - mean arterial blood pressure,

DBP - diastolic blood pressure,

SBP - systolic blood pressure.

All the subjects underwent ultrasonographic examinations of the liver, kidneys and thyroid gland. Demographic parameters, anthropometric measurements results, blood pressure, medications and laboratory and ultrasonographic results of the participants were directly recorded in a Microsoft Excel 2010 file. All the subjects gave their written informed consent to participate in the study. The study protocol was approved by The Research and Ethics Committees of Gulhane Military Medical Academy.

\section{Blood sample collection and analysis of parameters}

All blood samples were collected in the morning after at least $10 \mathrm{~h}$ of fasting. Routine laboratory tests and biochemistry including a full blood count, serum glucose, urea, uric acid, creatinine, sodium, potassium, liver enzymes, were performed during the control visit. Fasting plasma glucose, total cholesterol (TC), triglyceride and high-density lipoprotein cholesterol (HDL-C) levels were measured by means of the enzymatic colorimetric method with an Olympus AU2700 auto analyzer using reagents from Olympus Diagnostics GmbH (Hamburg, Germany). Low-density lipoprotein cholesterol (LDL-C) was calculated by the use of the Friedewald's formula [7]. Antithyrogloulin and antithyroid peroxidase antibodies were studied using standard enzyme-linked immunosorbent assay (ELISA) kits.

\section{Anthropometric measurements}

Weight (in $\mathrm{kg}$ ) and height (in $\mathrm{cm}$ ) were measured, and body mass index (BMI) was calculated as body weight/ height $^{2}\left(\mathrm{~kg} / \mathrm{m}^{2}\right)$.

\section{Calculation of the p-wave dispersion}

All the subjects had a 12-lead ECG on $10 \mathrm{mV}$ amplitude and $25 \mathrm{~mm} / \mathrm{s}$ velocity performed. On the ECG, p-waves were manually marked along the isoelectric line at the starting and ending points. P-waves the starting and ending points of which couldn't be analyzed exactly were excluded from the data analysis. The p-waves with the shortest and longest durations were established for each ECG separately. P-wave dispersion was calculated by subtracting the minimum durations of $\mathrm{p}$-waves from their maximum durations. A person indifferent to the groups and characteristics of the patients observed, and calculated the measurements. Then, the difference between the maximum and minimum $\mathrm{p}$-wave durations for the same subject was accepted as PWD.

\section{Statistical analysis}

Continuous variables with normal distribution were reported as mean \pm standard deviation $(\mathrm{M} \pm \mathrm{SD})$, whereas for non-normally distributed variables median (interquartile range - IQR) was used. Differences of normally distributed continuous variables between the groups were determined using the unpaired t-test, whereas the Mann-Whitney U test was used for nonnormally distributed continuous variables in comparisons. Categorical variables were compared by means of the $\mathrm{Chi}^{2}$ test. Pearson and Spearman correlation analyses were used to evaluate relationships between the variables. $\mathrm{P}$ of $<0.05$ was considered as statistically significant. Statistical analysis was carried out using IBM SPSS Statistics for Windows, version 22.0. (IBM Corp., USA). 


\section{RESULTS}

A total of 75 male aircrew were recruited. The mean age of the study participants was $36.15 \pm 8.97$ years. The mean values of demographic parameters, $p$-wave duration and dispersion, blood pressure and laboratory measurements of the study group are shown in Table 1. The lowest of minimum and the highest of maximum $\mathrm{p}$-wave durations were $52 \mathrm{~ms}$ and $156 \mathrm{~ms}$, respectively. The mean p-wave duration was $100.8 \pm 12 \mathrm{~ms}$ in the whole group.

Thirteen subjects were serving in jets, 49 in helicopters, and 13 were serving in transport aircrafts. Thirty-six of the helicopter and 11 of the transport aircraft aircrew were non-pilot aircrew. So, 47 of the total subjects were nonpilot aircrew, and 28 were pilots. P-wave dispersion was the lowest in the transport aircraft aircrew, and the highest in the jet pilots. In the ANOVA analysis, the jet, helicopter and transport aircraft aircrew groups were statistically similar in terms of age, BMI, mean arterial pressure, pulse rates, thyroid-stimulating hormone and hemoglobin levels, and were presented in Table 2. The difference in PWDs between the jet and transport aircraft aircrew was significant $(p=0.013$ ) (Figure 1). The mean PWD of the non-pilot aircrew and pilots were $37.3 \pm 12.3 \mathrm{~ms}$ and $41.9 \pm 13.8 \mathrm{~ms}$, respectively $(\mathrm{p}=0.159$ ) (Figure 2).

With regard to concomitant medical conditions, $23 \mathrm{sub-}$ jects were overweight $\left(\mathrm{BMI}>25 \mathrm{~kg} / \mathrm{m}^{2}\right), 19$ of the aircrew suffered from ultrasonographically documented thyroiditis, 26 had hepatosteatosis, 4 had hyperbilirubinemia (total bilirubin levels $>1.5 \mathrm{mg} / \mathrm{dl}$ ), 2 had high blood pressure measurements ( $>$ 140/90 mm Hg on 2 occasions), and 5 had hyperlipidemia (above normal range of lipid laboratory values). The PWD comparisons according to the aircraft types, tasks and medical conditions are shown in Table 3.

In the correlation analysis, the PWD was associated with TSH levels in the whole group $(r=0.279, \mathrm{p}=0.016)$ (Figure 3). In addition, serum uric acid levels were associated with the minimum, maximum and mean $\mathrm{p}$-wave

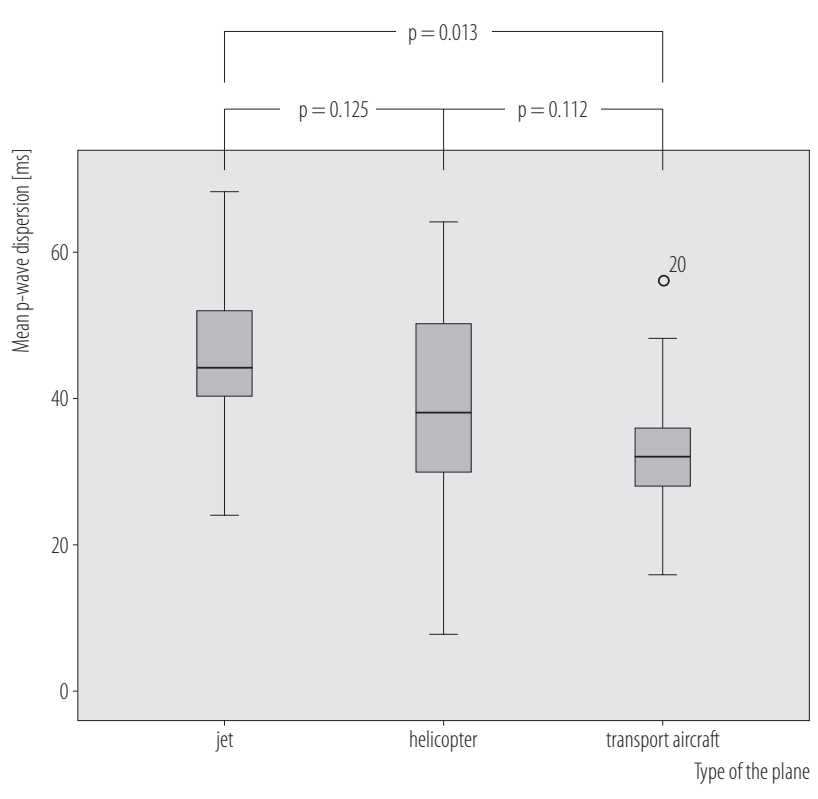

The jet pilots had significantly higher p-wave dispersions compared to the transport aircraft aircrew; the jet pilots also had p-wave dispersions higher than the helicopter aircrew, but the difference was statistically insignificant.

Fig. 1. The box-plot referring to the changes in the mean p-wave dispersions according to the aircraft types

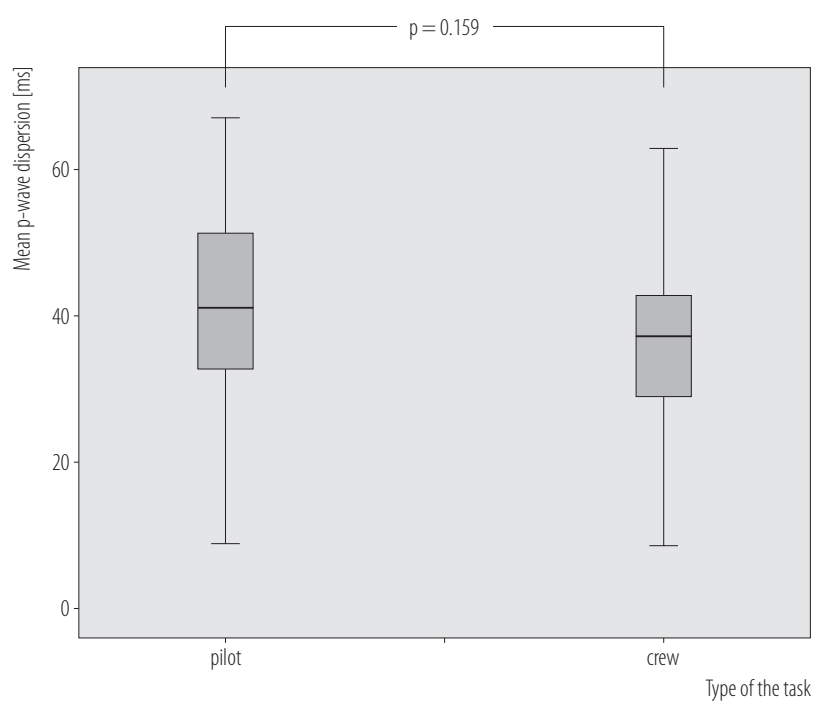

The pilots had higher p-wave dispersions compared to the non-pilot aircrew, but it was lacking significance.

Fig. 2. The box-plot referring to the changes in the mean $\mathrm{p}$-wave dispersions according to the type of tasks military aircrew 
Table 1. Characteristics of the study group

\begin{tabular}{|c|c|}
\hline Variable & $\begin{array}{c}\text { Study group } \\
(\mathrm{M} \pm \mathrm{SD})\end{array}$ \\
\hline Age [years] & $36.15 \pm 8.97$ \\
\hline Body mass index $(\mathrm{BMI})\left[\mathrm{kg} / \mathrm{m}^{2}\right]$ & $25.39 \pm 2.44$ \\
\hline p-wave dispersion [ms] & $39.03 \pm 13.02$ \\
\hline \multicolumn{2}{|l|}{ p-wave duration [ms] } \\
\hline M & $100.86 \pm 12.01$ \\
\hline $\min$. & $81.35 \pm 14.02$ \\
\hline $\max$ & $120.38 \pm 13.29$ \\
\hline \multicolumn{2}{|l|}{ Blood pressure [mm Hg] } \\
\hline systolic & $116.27 \pm 16.50$ \\
\hline diastolic & $73.60 \pm 9.95$ \\
\hline mean arterial & $87.82 \pm 11.36$ \\
\hline Pulse rate [beats/min] & $75.42 \pm 13.65$ \\
\hline Serum free $\mathrm{T} 3[\mathrm{pg} / \mathrm{dl}]$ & $3.41 \pm 0.37$ \\
\hline Serum free $\mathrm{T} 4$ [ng/dl] & $1.21 \pm 0.15$ \\
\hline Serum TSH [mIU/l] & $1.99 \pm 1.08$ \\
\hline Hemoglobin [g/dl] & $15.22 \pm 1.10$ \\
\hline Hematocrit [\%] & $44.56 \pm 2.79$ \\
\hline Mean corpuscular volume [fl] & $87.51 \pm 5.04$ \\
\hline Red cell distribution width [\%] & $12.39 \pm 1.62$ \\
\hline Platelet count $\left[\times 1000 / \mathrm{mm}^{3}\right]$ & $232.49 \pm 52.25$ \\
\hline White blood cell $\left[\times 1000 / \mathrm{mm}^{3}\right]$ & $7.28 \pm 1.77$ \\
\hline Sedimentation rate $[\mathrm{mm} / \mathrm{h}]$ & $5.55 \pm 3.90$ \\
\hline Serum fasting glucose $[\mathrm{mg} / \mathrm{dl}]$ & $93.48 \pm 10.50$ \\
\hline Serum urea $[\mathrm{mg} / \mathrm{dl}]$ & $26.33 \pm 5.22$ \\
\hline Serum creatinine $[\mathrm{mg} / \mathrm{dl}]$ & $0.99 \pm 0.14$ \\
\hline Serum uric acid [mg/dl] & $5.84 \pm 1.36$ \\
\hline Aspartate aminotranspherase [IU/ml] & $29.80 \pm 8.94$ \\
\hline Alanine aminotranspherase [IU/ml] & $37.41 \pm 16.86$ \\
\hline Serum alkaline phosphatase [IU/ml] & $69.68 \pm 22.66$ \\
\hline Serum total bilirubin [mg/dl] & $0.80 \pm 0.54$ \\
\hline Gamma-glutamyl transpeptidase [IU/ml] & $24.16 \pm 15.91$ \\
\hline Serum total cholesterol [mg/dl] & $203.49 \pm 39.99$ \\
\hline Serum triglyceride $[\mathrm{mg} / \mathrm{dl}]$ & $118.29 \pm 68.21$ \\
\hline Serum high density lipoprotein cholesterol [mg/dl] & $53.52 \pm 10.62$ \\
\hline Serum low density lipoprotein cholesterol [mg/dl] & $127.93 \pm 33.07$ \\
\hline
\end{tabular}

M - mean; SD - standard deviation; min. - minimal value; max - maximal value.

T3 - triiodothyronine; T4 - thyroxine; TSH - thyroid stimulating hormone. 
Table 2. Comparisons of the demographic characteristics, blood pressure and some laboratory tests results affecting p-wave dispersion (PWD) among the study groups

\begin{tabular}{|c|c|c|c|c|}
\hline \multirow[t]{2}{*}{ Variable } & \multicolumn{3}{|c|}{$\begin{array}{l}\text { Aircrew } \\
(\mathrm{M} \pm \mathrm{SD})\end{array}$} & \multirow{2}{*}{$\mathrm{p}$} \\
\hline & jet & helicopter & transport aircraft & \\
\hline Age [years] & $41.46 \pm 11.03$ & $35.08 \pm 8.77$ & $34.85 \pm 5.46$ & 0.061 \\
\hline $\mathrm{BMI}\left[\mathrm{kg} / \mathrm{m}^{2}\right]$ & $24.89 \pm 1.96$ & $25.54 \pm 2.40$ & $25.34 \pm 3.09$ & 0.702 \\
\hline Mean arterial pressure $[\mathrm{mm} \mathrm{Hg}]$ & $93.08 \pm 11.98$ & $86.46 \pm 11.41$ & $87.69 \pm 9.66$ & 0.176 \\
\hline Pulse rate [beats/min] & $76.46 \pm 9.78$ & $74.19 \pm 13.59$ & $78.92 \pm 17.16$ & 0.523 \\
\hline Serum TSH [mIU/l] & $2.28 \pm 1.01$ & $1.97 \pm 1.10$ & $1.77 \pm 1.06$ & 0.486 \\
\hline Hemoglobin $[\mathrm{g} / \mathrm{dl}]$ & $14.74 \pm 1.21$ & $15.37 \pm 1.16$ & $15.14 \pm 0.49$ & 0.178 \\
\hline
\end{tabular}

Abbreviations as in Table 1.

Table 3. The p-wave dispersion comparisons according to the presence of medical conditions, aircraft types, or being a pilot or non-pilot aircrew

\begin{tabular}{|c|c|c|c|c|c|c|}
\hline \multirow[b]{2}{*}{ Condition } & \multirow[b]{2}{*}{ Presence } & \multicolumn{3}{|c|}{$\begin{array}{c}\text { Study group } \\
{[\mathrm{n}]}\end{array}$} & \multirow{2}{*}{$\begin{array}{c}\text { Mean p-wave } \\
\text { dispersion } \\
{[\mathrm{ms}]} \\
(\mathrm{M} \pm \mathrm{SD})\end{array}$} & \multirow[b]{2}{*}{$\mathrm{p}$} \\
\hline & & $\begin{array}{l}\text { jet pilot } \\
(\mathrm{N}=13)\end{array}$ & $\begin{array}{l}\text { helicopter } \\
\text { aircrew } \\
(\mathrm{N}=49)\end{array}$ & $\begin{array}{c}\text { transport } \\
\text { aircraft aircrew } \\
(\mathrm{N}=13)\end{array}$ & & \\
\hline \multicolumn{7}{|l|}{ Medical status } \\
\hline \multirow[t]{2}{*}{ overweight $(\mathrm{N}=23)$} & yes & 2 & 16 & 5 & $40.17 \pm 14.60$ & 0.638 \\
\hline & no & 11 & 33 & 8 & $38.51 \pm 12.30$ & \\
\hline \multirow[t]{2}{*}{ thyroiditis $(\mathrm{N}=19)$} & yes & 2 & 15 & 2 & $42.95 \pm 13.90$ & 0.141 \\
\hline & no & 11 & 34 & 11 & $37.41 \pm 12.80$ & \\
\hline \multirow[t]{2}{*}{ hepatosteatosis $(\mathrm{N}=26)$} & yes & 3 & 17 & 6 & $37.85 \pm 13.60$ & 0.578 \\
\hline & no & 10 & 32 & 7 & $39.67 \pm 12.80$ & \\
\hline \multirow[t]{2}{*}{ hyperbilirubinemia $(\mathrm{N}=4)$} & yes & 1 & 3 & 0 & $45.33 \pm 18.90$ & 0.609 \\
\hline & no & 12 & 46 & 13 & $38.76 \pm 12.80$ & \\
\hline \multirow[t]{2}{*}{ hypertension ( $\mathrm{N}=2)$} & yes & 1 & 1 & 0 & $30.00 \pm 14.10$ & 0.052 \\
\hline & no & 12 & 48 & 13 & $39.20 \pm 13.00$ & \\
\hline \multirow[t]{2}{*}{ hyperlipidemia $(\mathrm{N}=5)$} & yes & 1 & 4 & 0 & $33.60 \pm 6.70$ & 0.133 \\
\hline & no & 12 & 45 & 13 & $39.40 \pm 13.30$ & \\
\hline \multirow[t]{2}{*}{ anti-TG positivity $(\mathrm{N}=5)$} & yes & 1 & 3 & 1 & $44.80 \pm 11.40$ & 0.638 \\
\hline & no & 12 & 46 & 12 & $41.00 \pm 16.80$ & \\
\hline \multirow[t]{2}{*}{ anti-TPO positivity $(\mathrm{N}=3)$} & yes & 0 & 3 & 0 & $45.30 \pm 14.04$ & 0.715 \\
\hline & no & 13 & 46 & 13 & $41.60 \pm 15.30$ & \\
\hline
\end{tabular}


Table 3. The p-wave dispersion comparisons according to the presence of medical conditions, aircraft types, or being a pilot or non-pilot aircrew - cont.

\begin{tabular}{|c|c|c|c|c|c|c|}
\hline \multirow[b]{2}{*}{ Condition } & \multirow[b]{2}{*}{ Presence } & \multicolumn{3}{|c|}{$\begin{array}{c}\text { Study group } \\
{[\mathrm{n}]}\end{array}$} & \multirow{2}{*}{$\begin{array}{c}\text { Mean p-wave } \\
\text { dispersion } \\
{[\mathrm{ms}]} \\
(\mathrm{M} \pm \mathrm{SD})\end{array}$} & \multirow[b]{2}{*}{$\mathrm{p}$} \\
\hline & & $\begin{array}{l}\text { jet pilot } \\
(\mathrm{N}=13)\end{array}$ & $\begin{array}{c}\text { helicopter } \\
\text { aircrew } \\
(\mathrm{N}=49)\end{array}$ & $\begin{array}{c}\text { transport } \\
\text { aircraft aircrew } \\
(\mathrm{N}=13)\end{array}$ & & \\
\hline \multicolumn{7}{|l|}{ Flying status } \\
\hline \multirow[t]{2}{*}{ jet pilot $(\mathrm{N}=13)$} & yes & 13 & 0 & 0 & $44.90 \pm 11.20$ & 0.057 \\
\hline & no & 0 & 49 & 13 & $37.70 \pm 13.10$ & \\
\hline \multirow[t]{2}{*}{ helicopter aircrew $(\mathrm{N}=49)$} & yes & 0 & 49 & 0 & $39.08 \pm 13.30$ & 0.960 \\
\hline & no & 13 & 0 & 13 & $38.90 \pm 12.70$ & \\
\hline \multirow[t]{2}{*}{ transport aircraft aircrew $(\mathrm{N}=13)$} & yes & 0 & 0 & 13 & $32.92 \pm 11.50$ & 0.053 \\
\hline & no & 13 & 49 & 0 & $40.30 \pm 13.05$ & \\
\hline \multirow[t]{2}{*}{ pilot $(\mathrm{N}=28)$} & yes & 13 & 13 & 2 & $41.86 \pm 13.80$ & 0.159 \\
\hline & no & 0 & 36 & 11 & $37.30 \pm 12.30$ & \\
\hline \multirow[t]{2}{*}{ non-pilot aircrew $(\mathrm{N}=47)$} & yes & 0 & 36 & 11 & $37.30 \pm 12.30$ & 0.159 \\
\hline & no & 13 & 13 & 2 & $41.86 \pm 13.80$ & \\
\hline
\end{tabular}

TG - thyroglobulin; TPO - thyroid peroxidase.

Other abbreviations as in Table 1.

durations $(\mathrm{r}=0.355, \mathrm{p}=0.002 ; \mathrm{r}=0.318, \mathrm{p}=0.006 ; \quad(\beta=0.258, \mathrm{p}=0.031)$. Other important predictors $\mathrm{r}=0.422, \mathrm{p}<0.001$, respectively) (Figure 4).

Regarding the regression analysis, serum TSH levof PWD included: HDL $(\beta=0.24)$, RDW $(\beta=0.20)$ and els were the most important predictor of PWD

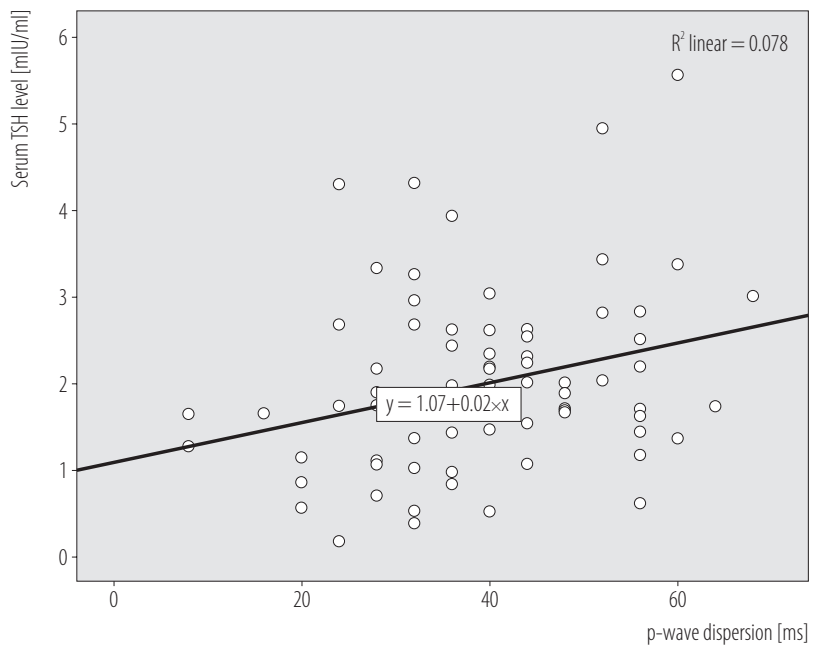

Fig. 3. The scatter-plots referring to the significant association between the p-wave dispersion and serum thyroid-stimulating hormone (TSH) levels being the transport aircraft aircrew $(\beta=0.22)$.

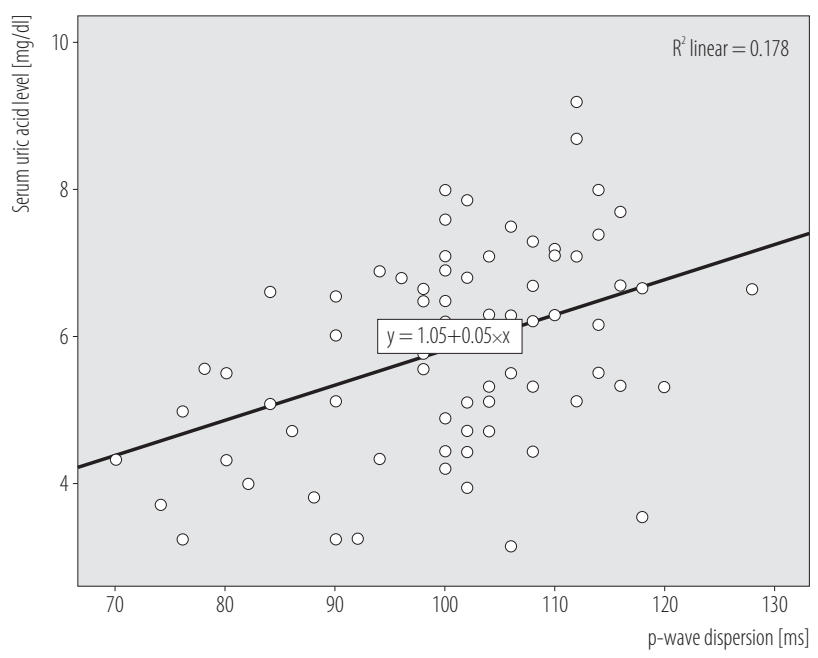

Fig. 4. The scatter-plots referring to the significant association between the p-wave duration and serum uric acid levels 


\section{DISCUSSION}

In this study we found that the jet pilots had significantly higher PWD levels, compared to the transport aircraft aircrew. There was a difference in the helicopter aircrew too, but it wasn't statistically significant. The fact that PWD was significantly associated with serum TSH levels in the military aircrew constitutes another important result of our study.

Arrhythmia is among the most frequent causes for military aircrew to be disqualified from flying tasks. Atrial fibrillation is the most common form of arrhythmia and it, especially, should not be disregarded, because it has a potential for sudden incapacitation during flight via acute hypotension or thromboembolic events, especially stroke. Atrial fibrillation affects cardiac output unfavorably and may cause acute incapacitation in flight due to the loss of the atrial systole, which mainly contributes to the diastolic filling of the ventricles. Atrial fibrillation is rare in pilots, but it is unacceptable in military aviation. A case report by Ozturk et al. has reported 2 cases of AF detected in jet pilots during aircrew periodical medical examinations [8]. In fact, we do not exactly know whether aviation itself causes $\mathrm{AF}$ in time, or if it is a random finding, and if there is a cause-effect relationship between flying, especially, jets and AF.

Atrial fibrillation is also the most common arrhythmia among hypertrophic cardiomyopathy patients. Such patients with concomitant paroxysmal AF have generally exercise intolerance, despite sinus rhythm at the exercise time [9]. There may be evidence that years of striving the heart to pump great volumes of blood for hours at a time, lead to long-term heart damage and, in fact, turn big health advantages of the aerobic exercise back. This subject has been speculated in the case of athletes, having AF years after a healthy athletic life. The big load on heart may lead to such problems. In our study, we found higher PWD in the jet pilots. This association was independent of other factors like: age, TSH levels, mean arterial pressure, pulse rates, hemoglobin values and BMI. We believe that in the case of jet pilots, big $\mathrm{G}$ forces, continuing Valsalva maneuvers, hypoxia, hypobaric conditions, and other compelling flying situations may be responsible for the higher PWD values. Further studies should be carried out to reveal the dynamic effects of challenging situations during flying a jet aircraft on $\mathrm{AF}$, and one of its important predictors, PWD.

Cardiac arrhythmias can be seen in hyperthyroidism, and according to some studies, in hypothyroidism. Hyperthyroidism is a well known risk factor for atrial fibrillation $[10,11]$. Hypothyroidism has also been reported to increase ventricular arrhythmias [12]. Hypothyroidism decreases myocyte-specific gene expression in the heart and changes the cardiac function [13]. It also leads to increased vascular resistance, a decreased cardiac output, bradycardia, diastolic hypertension and premature ventricular beats $[14,15]$.

Our study revealed a significant association between PWD and TSH levels in the military aircrew. Increasing TSH levels were found to be associated with increasing PWD, meaning that a decreasing thyroid gland and thyroid hormone activity was associated with increasing PWD. That is compatible with previous studies reporting higher PWD in hypothyroid patients. In fact, hypothyroidism has been reported as a risk factor for development of AF, and PWD may be a good marker of developing AF in the future. Hypothyroidism has been suggested to be as important as hyperthyroidism in the pathogenesis of atrial fibrillation [5]. There is a clear difference between hyperthyroidism and hypothyroidism in causing a PWD increase. In hyperthyroidism, the increased PWD has been found to be due to the increased maximum p-wave duration, whereas in hypothyroidism, the increased PWD has been reported to be due to the decreased minimum p-wave duration. We feel convinced that early recognition and treatment of hypothyroidism and hyperthyroidism, and reporting PWD in military aircrew in periodical examinations might help 
to prevent development of atrial fibrillation with its dare complications, like stroke [5].

We also found a significant correlation between serum uric acid and the minimum, maximum and mean p-wave durations in military aircrew. We do not exactly know the importance of this association, but this finding is compatible with the previous literature data. In a study by Su et al., studying the association of PWD and the maximum $\mathrm{p}$-wave duration with rapid renal function decline, it has been reported that the maximum p-wave duration and PWD were significantly associated with serum uric acid levels [16]. Elevated uric acid levels have an association with higher cardiovascular accidents [17]. This subject is open to further studies to reveal the associations.

Our study has some limitations. First, our study group was relatively small. Second, females are a smaller group compared to males in the military aircrew in our country, and we could not obtain any data about female military pilots. This may cause some controversy due to gender differences in this subject.

\section{CONCLUSIONS}

According to the results of our study, there were correlations between TSH levels and p-wave dispersion, and between serum uric acid levels and the mean p-wave duration in the, required to be completely healthy, military aircrew. The jet pilots had significantly higher PWD calculations. This reveals that military jet pilots may have a risk of atrial fibrillation in the future, and that they should be monitored in terms of this aspect. The p-wave dispersion is an important parameter to be considered during periodical examinations of the military aircrew.

\section{REFERENCES}

1. Villani GQ, Piepoli M, Rosi A, Capucci A. P-wave dispersion index: A marker of patients with paroxysmal atrial fibrillation. Int J Cardiol. 1996;55:169-75, http://dx.doi.org/10.1016/ 0167-5273(96)02677-0.
2. Deftereos S, Kossyvakis C, Efremidis M, Bouras G, Panagopoulou V, Papadimitriou C, et al. Interatrial conduction time and incident atrial fibrillation: A prospective cohort study. Heart Rhythm. 2014;11:1095-101, http://dx.doi. org/10.1016/j.hrthm.2014.03.053.

3. Gen R, Akbay E, Çamsari A, Özcan T. P-wave dispersion in endogenous and exogenous subclinical hyperthyroidism. J Endocrinol Invest. 2010;33:88-91, http://dx.doi.org/ 10.1007/BF03346559.

4. Guntekin U, Gunes Y, Simsek H, Tuncer M, Arslan S. P wave duration and dispersion in patients with hyperthyroidism and the short-term effects of antithyroid treatment. Indian Pacing Electrophysiol J. 2009;9:251-9.

5. Akdemir R, Eryaşar NE, Çelik K, Güngüneş A, Cinemre $\mathrm{H}$, Bilir $\mathrm{C}$, et al. Increased $\mathrm{P}$ wave dispersion in hypothyroidism: A sign of risk of atrial fibrillation. Turk J Med Sci. 2009;39:629-33, http://dx.doi.org/10.3906/sag-0808-3.

6. Dilaveris PE, Gialafos EJ, Sideris SK, Theopistou AM, Andrikopoulos GK, Kyriakidis M, et al. Simple electrocardiographic markers for the prediction of paroxysmal idiopathic atrial fibrillation. Am Heart J. 1998;135:733-8, http://dx.doi. org/10.1016/S0002-8703(98)70030-4.

7. Friedewald WT, Levy RI, Fredrickson DS. Estimation of the concentration of low-density lipoprotein cholesterol in plasma, without use of the preparative ultracentrifuge. Clin Chem. 1972;18:499-502.

8. Ozturk C, Akin A, Metin S, Cakmak T, Sen A. Atrial fibrillation in 2 jet pilots during aircrew periodical medical examination. Aviat Space Environ Med. 2012;83:706-10, http:// dx.doi.org/10.3357/ASEM.3286.2012.

9. Azarbal F, Singh M, Finocchiaro G, Le V-V, Schnittger I, Wang P, et al. Exercise capacity and paroxysmal atrial fibrillation in patients with hypertrophic cardiomyopathy. Heart. 2014;100:624-30, http://dx.doi.org/10.1136/ heartjnl-2013-304908.

10. Sawin CT, Geller A, Wolf PA, Belanger AJ, Baker E, Bacharach $\mathrm{P}$, et al. Low serum thyrotropin concentrations as a risk factor for atrial fibrillation in older persons. 
N Engl J Med. 1994;331:1249-52, http://dx.doi.org/10.1056/ NEJM199411103311901.

11. Auer J, Scheibner P, Mische T, Langsteger W, Eber O, Eber B. Subclinical hyperthyroidism as a risk factor for atrial fibrillation. Am Heart J. 2001;142:838-42, http://dx.doi. org/10.1067/mhj.2001.119370.

12. Marrakchi S, Kanoun F, Idriss S, Kammoun I, Kachboura S. Arrhythmia and thyroid dysfunction. Herz. 2015;40 Suppl 2: 101-9, http://dx.doi.org/10.1007/s00059-014-4123-0.

13. Danzi S, Klein I. Thyroid hormone and blood pressure regulation. Curr Hypertens Rep. 2003;5:513-20, http://dx.doi. org/10.1007/s11906-003-0060-7.

14. Stafford PJ, Kolvekar S, Cooper J, Fothergill J, Schlindwein F, Spyt TJ, et al. Signal averaged P wave compared with standard electrocardiography or echocardiography for prediction of atrial fibrillation after coronary bypass grafting. Heart. 1997;77:417-22, http://dx.doi.org/10.1136/ hrt.77.5.417.

15. Crowley WF Jr., Ridgway EC, Bough EW, Francis GS, Daniels GH, Kourides IA, et al. Noninvasive evaluation of cardiac function in hypothyroidism: Response to gradual thyroxine replacement. N Engl J Med. 1977;296:1-6, http://dx.doi. org/10.1056/NEJM197701062960101.

16. Su H-M, Tsai W-C, Lin T-H, Hsu P-C, Lee W-H, Lin $\mathrm{M}-\mathrm{Y}$, et al. $\mathrm{P}$ wave dispersion and maximum $\mathrm{P}$ wave duration are independently associated with rapid renal function decline. PLoS One. 2012;7:e42815, http://dx.doi. org/10.1371/journal.pone.0042815.

17. Feig DI. The role of uric acid in the pathogenesis of hypertension in the young. J Clin Hypertens (Greenwich). 2012;14:346-52, http://dx.doi.org/10.1111/j.1751-7176. 2012.00662.x

This work is available in Open Access model and licensed under a Creative Commons Attribution-NonCommercial 3.0 Poland License - http://creativecommons.org/ licenses/by-nc/3.0/pl/deed.en. 